\title{
Determination of Nickel, Manganese, Cobalt, and Iron in High-Temperature Alloys, Using Anion-Exchange Separations
}

\author{
John L. Hague, Edwin E. Maczkowske, and Harry A. Bright
}

\begin{abstract}
A procedure is given for the determination of nickel, manganese, cobalt, and iron in a high-temperature alloy. Niobium, tantalum, tungsten, and silicon are rendered insoluble by hydrochloric acid dehydration after solution of the alloy in aqua regia. Molybdenum and copper are precipitated with hydrogen sulfide, and the solution is filtered. The filtrate is evaporated several times with hydrochloric acid and hydrogen peroxide to obtain a chloride solution of these elements in the proper valence. The resulting solution is transferred to an anion-exchange column containing Dowex-1. The nickel and manganese, with chromium and some other elements, are collected in the first fraction by elution with $9 N$ hydrochloric acid. Cobalt is collected in a second fraction by elution with $4 \mathrm{~N}$ hydrochloric acid, and iron in a third by elution with $1 N$ hydrochloric acid. The cobalt is determined by electrolysis from a weakly ammoniacal chloride solution containing hydroxylamine hydrochloride, and the other elements are determined by conventional methods.
\end{abstract}

\section{Introduction}

The increased use in recent years of high-temperature alloys and alloys of controlled temperatureexpansion characteristics has made the problem of determining cobalt, iron, nickel, and manganese in appreciable quantities and in combination a pressing one. Some of the difficulties encountered in this field of analysis have been summarized by Chirnside, Cluley, and Proffitt [3] ${ }^{1}$ in dealing with a ternary alloy of iron, nickel, and cobalt. Many of the alloys manufactured today may contain, in addition, appreciable percentages of chromium, molybdenum, titanium, tungsten, niobium, and other elements. The problem of obtaining analyses of sufficient accuracy for the establishment of standards of composition is not an easy one; even the usually simple determination of nickel may become quite complex in these mixtures [7]. A new approach to the problem seems needed in order to put such methods on a basis of accuracy comparable to other less difficult combinations.

The present paper describes the application of anion-exchange separations to the analysis of hightemperature alloys. Kraus and Moore [8, 12] have shown that nickel, manganese, cobalt, and iron, as well as certain other elements, can be separated by selective elution from an anion-exchange resin with hydrochloric acid solutions. These separations depend on the fact that a number of metallic elements [10] can exist in aqueous solutions either as cations or as complex chloro-anions, the relative amounts depending on the element and on the concentration of chloride ions in the solution. The exact mechanism of the combination (or adsorption) of these complexes with the resin has not been established, but it may be related to the existence of these complex anions in solution as strong acids. For example, iron is probably combined in the form of a complex anion, such as $\left(\mathrm{H}_{2} \mathrm{FeCl}_{6}\right)^{-}$, that is free

Figures in brackets indicate the literature reference at the end of this paper. to compete with the chloride ions for a position on the resin column, much as the competition that exists between chloride and bisulfate ions [9]. Though suggested mechanisms are at present speculative, practical and efficient quantitative separations can be made with quantities and volumes commonly used in analytical work.

The procedure outlined below was designed particularly with the analysis of an S-816 type of alloy ${ }^{2}$ in mind. After solution of the alloy in aqua regia, the niobium, tantalum, tungsten, and silicon are rendered insoluble by hydrochloric-acid dehydration. The solution is treated with hydrogen sulfide to precipitate molybdenum and copper, and filtered. The filtrate is evaporated several times with hydrochloric acid and hydrogen peroxide to obtain a chloride solution of the elements in the proper valence. The resulting solution is transferred to an anion-exchange column, and the nickel and manganese, with chromium and some other elements, are collected in the first fraction by elution with $9 \mathrm{~N}$ hydrochloric-acid solution. Cobalt is collected in a second fraction by elution with $4 N$ hydrochloric acid, and iron in a third by elution with $1 \mathrm{~N}$ hydrochloric acid. Manganese and nickel are determined in aliquots of the first fraction by the persulfate-arsenite titration and dimethylglyoxime gravimetric methods, respectively. Cobalt is determined in the second fraction by electrolysis from a weakly ammoniacal chloride solution containing hydroxylamine hydrochloride, and iron is determined in the third fraction by reduction with stannous chloride and titration with dichromate.

The method requires several days to carry to completion as about $3 \mathrm{hr}$ are required for each of the ion-exchange fractionations. The method is not intended to replace rapid routine procedures, where they can be developed for a particular type [3] of material, but provides an independent checking procedure of general application.

2 This alloy contains approximately 40 percent of cobalt, 20 percent of nickel, 20 percent of chromium, and 4 percent each of niobium, tungsten, and molybdenum, the remainder being largely iron, manganese, carbon, and silicon. 


\section{Apparatus and Resins}

The apparatus required for an ion-exchange separation is simple, consisting of a glass column to hold the resin. The column used in this investigation, illustrated in figure 1 , is 1 in. in internal diameter and 12 in. long. As most of these separations require several hours, it is convenient to so arrange the columns that a number can be operated with minimum attention. Such an assembly is illustrated in figure 2. The solutions necessary for elution are

Figure 1. Ion-exchange column.
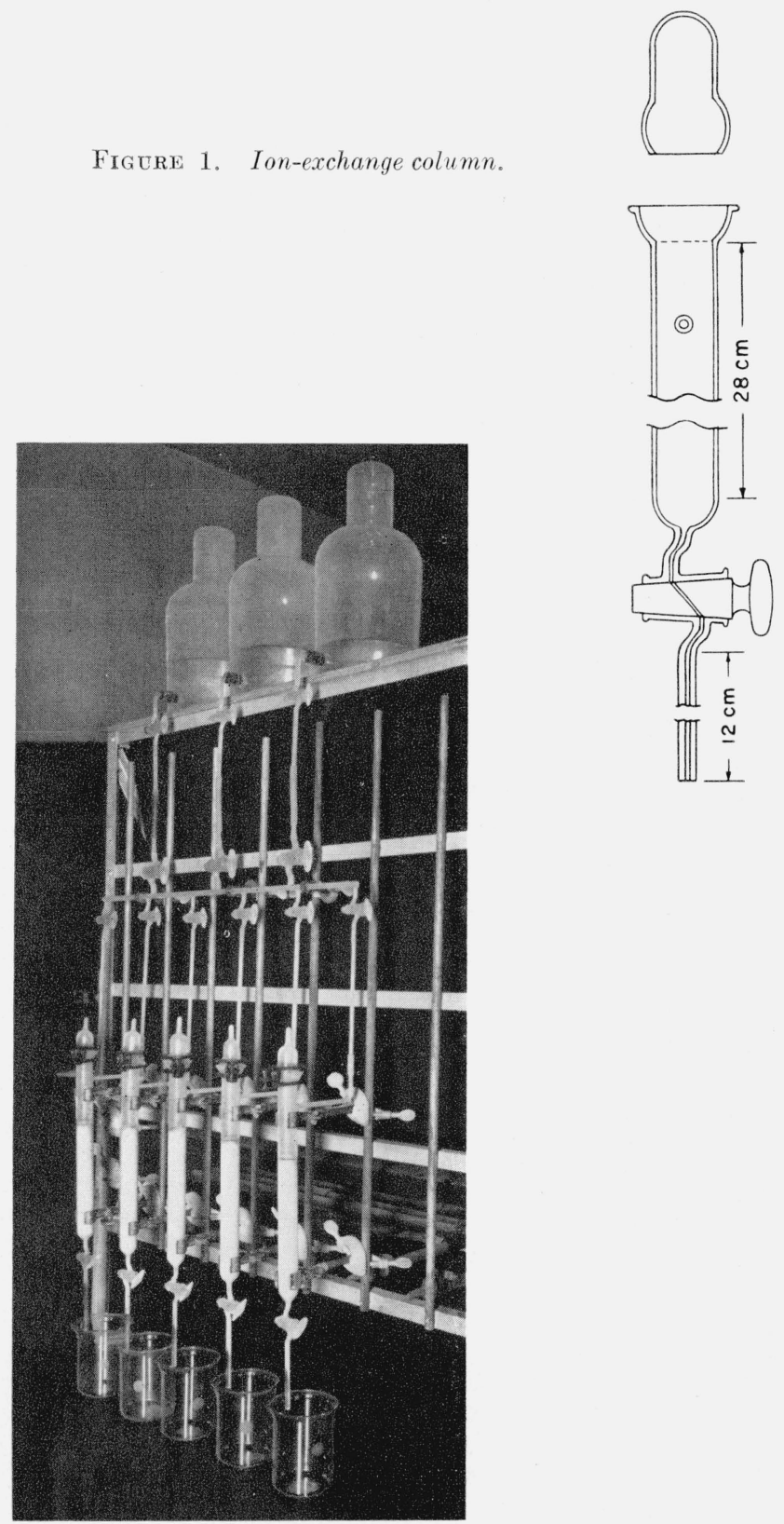

\subsection{Preparation of the Solution of the Sample for Ion-Exchange Separation}

Transfer an accurately weighed $1 \mathrm{~g}$ sample to a $600-\mathrm{ml}$ beaker. Cover the beaker and add $20 \mathrm{ml}$ of aqua regia (3 parts of hydrochloric acid and 1 part of nitric acid). Set the beaker on the side of a steam bath until the reaction ceases, and then warm it gently until the sample is in solution, ${ }^{5}$ except for small amounts of carbides and silica.

Wash the cover glass and wall of the beaker with a little diluted hydrochloric acid $(1+19)$ and evapporate to dryness on a steam bath. Treat the dry residue with $10 \mathrm{ml}$ of diluted hydrochloric acid $(1+1)$, warm and mix well with a glass rod, and again evaporate to dryness. Repeat the addition of diluted hydrochloric acid and the evaporation to dryness four times to insure the removal of nitric acid. ${ }^{6}$ Finally, add $15 \mathrm{ml}$ of diluted hydrochloric acid $(1+1)$ and warm the solution on the steam bath until the cake is dissolved. Dilute to $300 \mathrm{ml}$ with hot water, and pass a brisk stream of hydrogen sulfide through the solution for $30 \mathrm{~min}^{7}$ Let stand for $30 \mathrm{~min}$ and filter through a close-textured 11-cm paper containing a little paper pulp. Transfer the precipitate to the paper ${ }^{8}$ and wash with a diluted hydrochloric acid $(3+97)$ solution saturated with hydrogen sulfide until the volume of the filtrate and washings is at least $450 \mathrm{ml}$. Transfer the filtrate and washings to a steam bath and evaporate to dryness.

3 The fine-mesh resins were obtained from The Dow Chemical Co., Technical Service and Development, Midland, Mich.

4 This denotes 1 volume of concentrated hydrochloric acid, sp gr 1.18, diluted with 19 volumes of water. If no dilution is specified, the concentrated reagent is meant.

${ }^{5}$ Some alloys dissolve slowly, but will dissolve more readily if the chlorine generated by the acid mixture is not driven off by heat.

6 Manganese appears to form a complex chloromanganite anion of unknown composition in strong hydrochloric acid solutions in the presence of oxidizing agents.

${ }_{7}$ Molybdenum is absorbed in part by the ion-exchange column and soon contaminates all fractions during the separation procedure. It is conveniently removed at this point, along with the dehydrated silica, tungsten, tantalum, and removed at t
niobium.

${ }_{8}^{8}$ This paper can be ignited and the residue examined for manganese, nickel, cobalt, and iron. Examination of residues from an S-816 alloy indicated negligible quantities of manganese and iron, 0.01 percent of nickel, and 0.02 to 0.03 percent of cobalt to be retained by this precipitate. 
To the residue add $10 \mathrm{ml}$ of diluted hydrochloric acid $(1+1)$, cover the beaker with a watchglass, and warm. Add $50 \mathrm{ml}$ of warm water, and dissolve any residue on the walls of the beaker by manipulation of the solution with a glass rod. Add 10 drops of hydrogen peroxide $(30 \%)$ to the covered beaker and digest on a steam bath until reaction stops, then add an additional 10 drops of hydrogen peroxide. ${ }^{9}$ When reaction has ceased, wash the cover glass and beaker wall, and evaporate the solution to dryness. Add $10 \mathrm{ml}$ of diluted hydrochloric acid $(1+1)$, warm to dissolve salts, and again evaporate to dryness. Repeat the addition of diluted hydrochloric acid and evaporation to dryness four times.

Add $10 \mathrm{ml}$ of diluted hydrochloric acid $(1+1)$ to the residue, cover the beaker, and warm until the solution clears. Cool, add $10 \mathrm{ml}$ of hydrochloric acid, and mix well with a stirring rod. ${ }^{10}$ The solution is now ready for passage through the anionexchange column.

\subsection{Ion-Exchange Separation of Nickel and Man- ganese, Cobalt, and Iron}

Transfer $50 \mathrm{ml}$ of diluted hydrocbloric acid $(3+1)$ to the column in small increments ( 5 to $10 \mathrm{ml}$ ), and drain the acid to about $1 \mathrm{~cm}$ above the top mat. Place a small funnel in the top of the column. Transfer the concentrated solution of the sample in small increments $(5 \mathrm{ml})$ to the column with the bottom stopcock open. Add the sample as the solution moves down the column until all the sample has been transferred to the column. Always keep the resin completely covered with solution to prevent the formation of air pockets. Replace the "waste" beaker under the column with a clean $600-\mathrm{ml}$ beaker. Wash the beaker that contained the sample with 5$\mathrm{ml}$ portions of diluted hydrochloric acid $(3+1)$, policing the walls with a glass rod, and transfer the washings to the funnel and column until 10 washings have been made. The important point is to get all of the sample solution onto the resin bed. Finally, wash the funnel and the walls of the column above the resin with several small portions of the diluted hydrochloric acid $(3+1)$; a dropping tube and bulb is useful at this point.

Place the cap on the column top, lubricating the joint with a drop or two of water to prevent air leakage, and clamp. Adjust the stopcocks to deliver the diluted hydrochloric acid $(3+1)$ from the reservoir bottle to the column, and adjust the bottom stopcock on the column to a flow rate of 100 to $125 \mathrm{ml} / \mathrm{hr}$. Collect $425 \mathrm{ml}$ of solution, then adjust the stopcocks to deliver diluted hydrochloric acid $(1+2)$ to the column. After $15 \mathrm{~min}$ the more dilute acid will be about half way down the column, the beaker containing the nickel and manganese, along with chromium and some other elements, is then replaced with a clean $600-\mathrm{ml}$ beaker. Place the beaker containing the nickel and manganese on a steam bath and evaporate to dryness.

${ }^{9}$ This treatment is to remove any residual sulfide by oxidation. It also serves to oxidize any iron to the trivalent form required for the ion-exchange separation. 10 This treatment adjusts the solution to approximately $9 \mathrm{~N}$ hydrochloric acid, which is the correct acidity for the first step of the ion-exchange separation.
Continue the flow of diluted hydrochloric acid $(1+2)$ at a rate of 100 to $125 \mathrm{ml} / \mathrm{hr}{ }^{11}$ until $425 \mathrm{ml}$ of the cobalt fraction is obtained, then change the stopcocks to deliver diluted hydrochloric acid $(1+11)$. Replace the beaker containing the cobalt with a clean $600-\mathrm{ml}$ beaker and follow the procedure outlined in the previous paragraph. Place the beaker containing the cobalt on a steam bath, and evaporate the solution to dryness.

Continue the flow of diluted hydrochloric acid $(1+11)$, at a rate of 100 to $125 \mathrm{ml} / \mathrm{hr}$, until $450 \mathrm{ml}$ of the iron fraction is obtained. Close the stopcocks, transfer the beaker to a steam bath, and evaporate the solution to dryness.

\subsection{Determination of Nickel, Manganese, Cobalt, and Iron}

a. Nickel

Reagents

Citric acid solution (250 g/liter). Dissolve $250 \mathrm{~g}$ of citric acid in 600 to $800 \mathrm{ml}$ of water, add $20 \mathrm{ml}$ of diluted sulfuric acid $(1+1)$, and dilute to $1,000 \mathrm{ml}$ with water. Filter, if necessary.

Dimethylglyoxime solution (10 g/liter of ethanol). Dissolve $10 \mathrm{~g}$ of dimethylglyoxime in 1 liter of ethanol, and filter.

\section{Procedure}

Add $10 \mathrm{ml}$ of diluted hydrochloric acid $(1+1)$ to the reserved beaker containing the first fraction from the ion-exchange column, and warm to dissolve the residue. Dilute to $25 \mathrm{ml}$ with warm water, transfer to a $200-\mathrm{ml}$ volumetric flask, policing the beaker well. Cool to room temperature, dilute to the mark, and mix well. Transfer a 50-ml aliquot to a $400-\mathrm{ml}$ beaker, and reserve the remainder of the solution in the volumetric flask for the determination of manganese.

Add $5 \mathrm{ml}$ of hydrochloric acid and $25 \mathrm{ml}$ of citric acid solution to the aliquot in the beaker. Dilute to $100 \mathrm{ml}$ with warm water, and neutralize with ammonium hydroxide, using litmus paper as an indicator. Filter the solution ${ }^{12}$ through a $9-\mathrm{cm}$ closetextured paper containing a little pulp into a $600-\mathrm{ml}$ beaker and wash well with hot water.

Adjust the filtrate to a volume of $300 \mathrm{ml}$ and add an excess of 2 to $3 \mathrm{ml}$ of ammonium hydroxide. Add $0.4 \mathrm{ml}$ of dimethylglyoxime solution for each milligram of nickel (in the aliquot) and then $5 \mathrm{ml}$ in excess. Digest for $30 \mathrm{~min}$ on a steam bath with occasional stirring, and cool to room temperature. Filter through a weighed $30-\mathrm{ml}$ fritted-glass crucible of medium or fine porosity. Transfer the precipitate to the crucible and finally wash 4 or 5 times with cold water. Dry the precipitate to constant weight at

11 The lower viscosity of the more dilute acid usually requires a readjustment of the stopcock at the bottom of the column to maintain the specified flow.

12 The solution is usually cloudy with resin dissolved in the strong hydrochloric acid used for elution. The paper can be ignited, treated with $\mathrm{H}_{2} \mathrm{SO}_{4}-\mathrm{HF}$ to eliminate silica, and the residue dissolved in a few drops of $\mathrm{HCl}$ and returned to the main solution. 
$150^{\circ} \mathrm{C}$. Cool in a desiccator and weigh as nickel dimethylglyoxime.

\section{b. Manganese}

\section{ReAGents}

Sodium hydroxide solution (300 g/liter). Transfer $30 \mathrm{~g}$ of $\mathrm{NaOH}$ to a $250-\mathrm{ml}$ beaker, dissolve in $50 \mathrm{ml}$ of water, and dilute to $100 \mathrm{ml}$.

\section{Sodium bromate.}

Mixed-acid solution. Add $100 \mathrm{ml}$ of sulfuric acid to $675 \mathrm{ml}$ of water slowly with good stirring. Cool, and add $125 \mathrm{ml}$ of phosphoric acid $(85 \%)$ and $100 \mathrm{ml}$ of nitric acid.

Standard sodium arsenite solution $(1 \mathrm{ml}=0.4 \mathrm{mg}$ of $\mathrm{Mn}$ ). Transfer $4.8 \mathrm{~g}$ of $\mathrm{As}_{2} \mathrm{O}_{3}$ to a 600-ml beaker, add $50 \mathrm{ml}$ of water and $6 \mathrm{~g}$ of $\mathrm{NaOH}$. Stir until the oxide has dissolved, dilute to $300 \mathrm{ml}$ with water, and bubble a stream of carbon dioxide into the solution until it is saturated with $\mathrm{CO}_{2}$. Dilute with water to 4 liters in a glass-stoppered bottle, and mix well. The solution is standardized by titration of known amounts of manganese oxidized with persulfate.

\section{Silver nitrate solution ( $8 \mathrm{~g}$ per liter).}

Ammonium persulfate solution (250 g per liter). This solution is not stable, and should be prepared as needed.

\section{Procedure}

Transfer a 100-ml aliquot of the solution reserved from the nickel determination to a 400-ml beaker, and dilute to a volume of about $225 \mathrm{ml}$ with warm water. Add the sodium hydroxide solution dropwise until the solution is faintly acid, as judged by the redissolving of the precipitate. Add $3 \mathrm{~g}$ of sodium bromate and slowly bring to boiling temperature to oxidize the chromium. Remove from the heat, make just alkaline with the sodium hydroxide solution, and then add $10 \mathrm{ml}$ in excess. Boil gently a minute or two, and allow the precipitate containing the manganese to settle on a steam bath for a few minutes. Filter the hot solution through an 11-cm loose-textured paper containing a little paper pulp and wash 2 or 3 times with a little hot water. Return the paper and precipitate to the beaker, ${ }^{13}$ add $10 \mathrm{ml}$ of nitric acid, and mascerate the paper with a glass rod. Warm on a steam bath for a few minutes until the filter is disintegrated, and add $10 \mathrm{ml}$ of water containing a few drops of sulfurous acid. Digest until the precipitate dissolves, dilute with $50 \mathrm{ml}$ of hot water, and boil gently a minute or two. Allow to settle, filter ${ }^{14}$ through a 9 -cm loose-textured paper, and wash well with hot diluted nitric acid $(5+95)$. Evaporate the filtrate to dryness.

Add $30 \mathrm{ml}$ of acid mixture to the dry residue and digest until complete solution is obtained. Add 100

13 Alternatively, the paper can be decomposed by fuming with the mixed acid solution and several additions of $\mathrm{HNO}_{3}$ to destroy the paper. The final nitric acid concentration during the development of the permanganate color is critical, and the solution should contain no more than $3 \mathrm{ml}$ of $\mathrm{HNO}_{3}$.

14 The paper can be ignited, treated with $\mathrm{H}_{2} \mathrm{SO}_{4}-\mathrm{HF}$, and any residue can be dissolved in a few drops of $\mathrm{HNO}_{3}$ and added to the main solution. $\mathrm{ml}$ of hot water, $10 \mathrm{ml}$ of silver nitrate solution, and $10 \mathrm{ml}$ of ammonium persulfate solution. Bring to a boil, and boil briskly for 60 to $90 \mathrm{sec}$. Cool to a temperature of $15^{\circ} \mathrm{C}$ or lower, add $75 \mathrm{ml}$ of cold water with stirring, and titrate potentiometrically with the standard sodium arsenite solution to the first permanent break.

\section{c. Cobalt}

\section{Procedure}

Add $20 \mathrm{ml}$ of diluted nitric acid $(1+1)$ to the cobalt residue obtained from the second fraction of the ion-exchange separation. Cover the beaker and digest on a steam bath until the salts are in solution. Add $3 \mathrm{ml}$ of perchloric acid, and dissolve any residue on the walls of the beaker by manipulation of the solution with the glass rod. Transfer the beaker to a hot plate and evaporate to fumes of perchloric acid. Cool, add $5 \mathrm{ml}$ of nitric acid, police the walls of the beaker, and again evaporate the solution to fumes of perchloric acid. Repeat the procedure twice more to destroy the resin. ${ }^{15}$ Continue the heating to volatilize most of the perchloric acid, and to convert most of the salt to black oxide.

Cool, add $10 \mathrm{ml}$ of diluted hydrochloric acid $(1+1)$, and warm to dissolve the oxide. Add $10 \mathrm{ml}$ of hot water, and digest until the oxide is in solution. Remove and wash the cover glass, and evaporate the solution to dryness. Repeat the addition of $10 \mathrm{ml}$ of diluted hydrochloric acid $(1+1)$ and evaporation to dryness twice to insure decomposition of nitrates. ${ }^{16}$

Add $30 \mathrm{ml}$ of diluted hydrochloric acid $(1+1)$ to the dried residue and warm to dissolve the salts. Transfer the solution to a $400-\mathrm{ml}$ beaker, washing well with hot water. Adjust the volume to about $150 \mathrm{ml}$ and cool. Neutralize the solution by the dropwise addition of ammonium hydroxide. ${ }^{17}$ Add $1 \mathrm{~g}$ of hydroxylamine hydrochloride and stir well for a minute or two while the salt is dissolving. Add $5 \mathrm{ml}$ of ammonium hydroxide in excess, and dilute to approximately $275 \mathrm{ml}$ with water.

Transfer the solution to an electrolysis apparatus, cover with a split watchglass, and electrolyze overnight with platinum-gauze electrodes, using a current density of $0.4 \mathrm{amp} / \mathrm{dm}^{2}$. In the morning, wash the underside of the cover glass, and continue the electrolysis for $30 \mathrm{~min}$. Without interrupting the current, slowly lower the beaker, and at the same time, wash the electrodes with a stream of water. ${ }^{18}$ Immediately immerse the electrodes several times in a beaker of water. Interrupt the current and remove the cathode. Rinse the cathode with ethyl alcohol, shake off the excess alcohol, and dry at $110^{\circ} \mathrm{C}$ in an an oven for a few minutes. Cool in a desiccator, and weigh the deposit as metallic cobalt.

\footnotetext{
${ }_{15}$ Anion-exchange resins usually contain quaternary amine cations and may contaminate a cathode deposit in the electrolysis that follows.

${ }_{16}$ Nitrates inhibit or completely prevent the deposition of cobalt.

17 A small strip of Hydrion paper will conveniently indicate approximate neutrality,

${ }_{18}$ The electrolyte usually contains from 0.2 to $1 \mathrm{mg}$ of Co. A suitable aliquot can be heated with nitric acid to destroy ammonium salts, and the cobalt determined by the nitroso- $\mathrm{R}$ photometric method.
} 


\section{d. Iron}

\section{REAGENTS}

Potassium-permanganate solution (25 g/liter).

Stannous chloride solution (150 g/liter of diluted hydrochloric acid $(1+3))$. Dissolve $150 \mathrm{~g}$ of $\mathrm{SnCl}_{2} \cdot 2 \mathrm{H}_{2} \mathrm{O}$ in $500 \mathrm{ml}$ of diluted hydrochloric acid $(1+1)$, warming if necessary. Cool and dilute to 1 liter with water.

Mercuric chloride solution (approximately $60 \mathrm{~g} / \mathrm{liter}$ ). Prepare a saturated solution of $\mathrm{HgCl}_{2}$ in water.

Sulfuric-phosphoric acid solution. Mix $150 \mathrm{ml}$ of sulfuric acid with $300 \mathrm{ml}$ of water, cool, add $150 \mathrm{ml}$ of phosphoric acid $(85 \%)$, and dilute to 1 liter with water.

Sodium diphenylamine sulfonate indicator solution $(0.01 M)$. Transfer $0.32 \mathrm{~g}$ of barium diphenylamine sulfonate and $0.5 \mathrm{~g}$ of $\mathrm{Na}_{2} \mathrm{SO}_{4}$ to a $250-\mathrm{ml}$ Erlenmeyer flask, add $100 \mathrm{ml}$ of water, and mix well. Decant the supernatant liquid from the precipitated $\mathrm{BaSO}_{4}$.

Standard potassium dichromate solution $(0.1 N)$. Transfer $4.904 \mathrm{~g}$ of $\mathrm{K}_{2} \mathrm{Cr}_{2} \mathrm{O}_{7}$ (National Bureau of Standards Standard Sample 136) to a 1-liter volumetric flask, dissolve in a little water, dilute to the mark, and mix well.

\section{Procedure}

Add $10 \mathrm{ml}$ of diluted hydrochloric acid $(1+1)$ to the beaker containing the dried residue from the third fraction containing the iron. Cover the beaker, and warm until a clear solution is obtained. Dilute to about $25 \mathrm{ml}$ with hot water and add five drops of $\mathrm{KMnO}_{4}$ solution and stir. Heat to boiling, and boil gently for a few minutes to expel free chlorine. Add stannous chloride solution dropwise and with good stirring, until the color of the ferric chloride is discharged, and then 1 or 2 drops (no more) in excess. Wash down the inside of the beaker and cover glass, and quickly cool in ice water. Add, at one stroke, $10 \mathrm{ml}$ of saturated mercuric chloride solution, stir well, and again wash down the inside of the beaker with cool water. Allow the solution to stand for 2 to $5 \mathrm{~min}$.

Dilute to $200 \mathrm{ml}$ with cold water, add $20 \mathrm{ml}$ of sulfuric-phosphoric acid mixture and 4 drops of indicator solution. Titrate the reduced iron with a standard potassium dichromate solution to a clear blue or blue-green end point, which should be permanent for 30 sec.

\section{Results and Discussion}

The results obtained on a series of synthetic solutions made to simulate some of the cobalt- and nickel-base alloys of interest are given in table 1 . Nickel and iron were added as weighed portions of the high-purity metals, manganese was added as aliquots of a manganous nitrate solution prepared from high-purity manganese metal, and cobalt was added as aliquots of a cobalt chloride solution standardized by electrolysis.
The nickel and manganese values require little comment, recoveries being within the limits usually obtained in conventional methods of analysis.

The cobalt recoveries are based on a solution standardized by electrolysis and on a determination finished by electrolysis, and demonstrate the completeness of the recovery in the analytical procedure. They do not, however, indicate the accuracy of the electrolytic procedure for the determination of cobalt. To learn something of the accuracy of the electrolytic deposition method for the determination of cobalt, a batch of approximately $250 \mathrm{~g}$ of $\mathrm{Co}\left(\mathrm{NH}_{3}\right)_{6} \mathrm{Cl}_{3}$ was prepared [4] from reagent grade $\mathrm{CoCl}_{2} \cdot 6 \mathrm{H}_{2} \mathrm{O}$.

The salt was purified by precipitating three times from diluted hydrochloric acid $(1+10)$, finally recrystallizing from water, and drying in a vacuum desiccator over magnesium perchlorate and sodaasbestos. Weighed portions of 3 to $5 \mathrm{~g}$ were assayed by reduction to metal under hydrogen in a Rosetype crucible constructed of Vycor. The average of five determinations, involving $21 \mathrm{~g}$ of the salt, was 22.041 percent of cobalt, compared to a calculated value of 22.046 percent of cobalt, based on the weight in air of the salt. The salt was apparently quite uniform, the individual values all being within one part in a thousand of the average. The purification process was also effective in reducing the nickel content of the original cobalt salt from 0.08 percent to approximately 0.001 percent of nickel.

Portions of the salt were converted to cobalt sulfate by solution in $20 \mathrm{ml}$ of water and $20 \mathrm{ml}$ of diluted sulfuric acid $(1+1)$ and evaporation to fumes. Cobalt was deposited electrolytically from an ammoniacal ammonium sulfate-sulfite electrolyte, as usually recommended [5]. The values obtained are given in table 2, along with similar data obtained by plating the salt in ammoniacal ammonium chloride solution containing hydroxylamine hydrochloride under the conditions of the recommended procedure. The deposits from the sulfate-sulfite electrolytes are corrected for deposited sulfide sulfur, and all deposits are corrected for the cobalt remaining in the electrolyte. The latter correction was made in a suitable aliquot of the electrolyte by the Nitroso-R-photometric method. The electrolyte contained an average of $0.8 \mathrm{mg}$ of cobalt with a plating current of 0.25 $\mathrm{amp} / \mathrm{dm}^{2}$, and an average of $0.6 \mathrm{mg}$ of cobalt with 0.4 $\operatorname{amp} / \mathrm{dm}^{2}$.

The data demonstrate that the electrolytic method for cobalt gives high values similar to those obtained for nickel [6] and that the values obtained by deposition from the chloride solutions are the more nearly correct. The data are typical of approximately 100 determinations [11] made under both conditions from aliquots of several cobalt chloride solutions. The deposition from chloride solution eliminates the necessity for making a sulfur correction.

The recovery of iron is not entirely satisfactory as shown in table 1 , the values tending to run 5 or 6 parts in a thousand low. Experiments to determine where the iron was lost in the procedure showed approximately one part in a thousand to be in the 
TARLE 1. Results obtained for nickel, manganese, cobalt, and iron by the recommended procedure on synthetic mixtures

\begin{tabular}{|c|c|c|c|c|c|c|c|c|c|c|c|c|}
\hline \multirow{2}{*}{ Experiment number } & \multicolumn{3}{|c|}{ Nickel } & \multicolumn{3}{|c|}{ Manganese } & \multicolumn{3}{|c|}{ Cobalt } & \multicolumn{3}{|c|}{ Iron } \\
\hline & Taken & Found & Difference & Taken & Found & Difference & Taken & Found & Difference & Taken & Found & Difference \\
\hline $\begin{array}{l}1 . . \\
2 . \\
3 . \\
4- \\
5 .\end{array}$ & $\begin{aligned} g \\
0.4000 \\
.4004 \\
.4002 \\
.0505 \\
.0500\end{aligned}$ & $\begin{array}{c}g \\
0.3998 \\
.4000 \\
.4001 \\
.0503 \\
.0499\end{array}$ & $\begin{array}{c}g \\
-0.0002 \\
-.0004 \\
-.0001 \\
-.0002 \\
-.0001\end{array}$ & $\begin{array}{l}m g \\
10.0 \\
10.0 \\
10.0 \\
10.0 \\
10.0\end{array}$ & $\begin{array}{l}m g \\
10.01 \\
10.02 \\
10.01 \\
9.99 \\
9.99\end{array}$ & $\begin{array}{r}m G \\
0.01 \\
.02 \\
.01 \\
-.01 \\
-.01\end{array}$ & $\begin{aligned} \stackrel{g}{2} \\
0 . \\
.4210 \\
.4210 \\
.6311 \\
.6311\end{aligned}$ & $\begin{array}{l}g \\
0.4212 \\
.4215 \\
.4211 \\
.6313 \\
.6306\end{array}$ & $\begin{array}{r}g \\
0.0002 \\
.0005 \\
.0001 \\
.0002 \\
-.0005\end{array}$ & $\begin{array}{r}g \\
0.2005 \\
.1004 \\
.0509 \\
.3008 \\
.1004\end{array}$ & $\begin{array}{c}g \\
0.1990 \\
.0997 \\
.0504 \\
.2991 \\
.0994\end{array}$ & $\begin{array}{c}g \\
-0.0015 \\
-.0007 \\
-.0005 \\
-.0017 \\
-.0010\end{array}$ \\
\hline $\begin{array}{l}6 \ldots \\
7 . . \\
8 \\
9 \ldots \\
10\end{array}$ & $\begin{array}{l}.4003 \\
.4004 \\
.4004 \\
.0506 \\
.0507\end{array}$ & $\begin{array}{l}.4006 \\
.4007 \\
.4004 \\
.00508 \\
.0508\end{array}$ & $\begin{array}{l}.0003 \\
.0003 \\
.0000 \\
.0002 \\
.0001\end{array}$ & $\begin{array}{l}10.0 \\
10.0 \\
10.0 \\
10.0 \\
10.0\end{array}$ & $\begin{array}{r}10.01 \\
10.02 \\
10.02 \\
9.95 \\
9.97\end{array}$ & $\begin{array}{r}.01 \\
.02 \\
.02 \\
-.05 \\
-.03\end{array}$ & $\begin{array}{l}.4212 \\
.4212 \\
.4212 \\
.6314 \\
.6314\end{array}$ & $\begin{array}{l}.4219 \\
.4222 \\
.4219 \\
.6314 \\
.6311\end{array}$ & $\begin{array}{r}.0007 \\
.0010 \\
.0007 \\
.0000 \\
-.0003\end{array}$ & $\begin{array}{l}.2005 \\
.1005 \\
.0503 \\
.3004 \\
.1000\end{array}$ & $\begin{array}{l}.1993 \\
.1000 \\
.0498 \\
.2993 \\
.0994\end{array}$ & $\begin{array}{l}-.0012 \\
-.0005 \\
-.0005 \\
-.0011 \\
-.0006\end{array}$ \\
\hline $\begin{array}{l}11 \ldots \\
12 \ldots \\
13 \ldots \\
14 \ldots \\
15\end{array}$ & $\begin{array}{l}.4002 \\
.4004 \\
.4004 \\
.0500 \\
.0503\end{array}$ & $\begin{array}{l}.3998 \\
.4001 \\
.4000 \\
.0500 \\
.0504\end{array}$ & $\begin{array}{r}-.0004 \\
-.0003 \\
-.0004 \\
.0000 \\
.0001\end{array}$ & $\begin{array}{l}10.0 \\
10.0 \\
10.0 \\
10.0 \\
10.0\end{array}$ & $\begin{array}{l}10.04 \\
10.03 \\
10.03 \\
10.03 \\
10.03\end{array}$ & $\begin{array}{l}.04 \\
.03 \\
.03 \\
.03 \\
.03\end{array}$ & $\begin{array}{l}.4211 \\
.4211 \\
.4211 \\
.6313 \\
.6313\end{array}$ & $\begin{array}{l}.4216 \\
.4217 \\
.4215 \\
.6311 \\
.6310\end{array}$ & $\begin{array}{r}.0005 \\
.0006 \\
.0004 \\
-.0002 \\
-.0003\end{array}$ & $\begin{array}{l}.2000 \\
.1007 \\
.0504 \\
.3006 \\
.1004\end{array}$ & $\begin{array}{l}.1993 \\
.1002 \\
.0500 \\
.2995 \\
.0996\end{array}$ & $\begin{array}{l}-.0007 \\
-.0005 \\
-.0004 \\
-.0011 \\
-.0008\end{array}$ \\
\hline
\end{tabular}

TARLE 2. Results obtained for cobalt by the electrolysis of $\mathrm{Co}\left(\mathrm{NH}_{3}\right)_{6} \mathrm{Cl}_{3}$

\begin{tabular}{|c|c|c|c|c|c|c|c|}
\hline \multicolumn{2}{|c|}{ Taken } & \multirow{2}{*}{$\begin{array}{l}\text { Weight of } \\
\text { deposit }\end{array}$} & \multirow{2}{*}{$\begin{array}{l}\text { Cobalt in } \\
\text { electrolyte }\end{array}$} & \multirow{2}{*}{$\begin{array}{l}\text { Sulfur in } \\
\text { deposit }\end{array}$} & \multirow{2}{*}{$\begin{array}{l}\text { Cobalt } \\
\text { found }\end{array}$} & \multirow{2}{*}{ Difference } & \multirow{2}{*}{ Remarks } \\
\hline $\mathrm{Co}\left(\mathrm{NH}_{3}\right)_{6} \mathrm{Cl}_{3}$ & Cobalt & & & & & & \\
\hline $\begin{array}{c}g \\
0.2500 \\
.2500 \\
2.0000 \\
2.0000 \\
3.0000 \\
3.0000\end{array}$ & $\begin{array}{c}g \\
\text { 0. } 0551 \\
.0551 \\
.4408 \\
.4408 \\
.6612 \\
.6612\end{array}$ & $\begin{array}{c}g \\
0.0555 \\
. .564 \\
.4426 \\
.4438 \\
.6647 \\
.6641\end{array}$ & $\begin{array}{c}g \\
0.0009 \\
.0008 \\
.0017 \\
.0009 \\
.0008 \\
.0009\end{array}$ & $\begin{array}{c}g \\
0.0003 \\
.0002 \\
.0014 \\
.0015 \\
.0022 \\
.0018\end{array}$ & $\begin{array}{c}g \\
0.0561 \\
.0570 \\
.4429 \\
.4432 \\
.6633 \\
.6632\end{array}$ & $\begin{array}{c}g \\
0.0010 \\
.0019 \\
.0021 \\
.0024 \\
.0021 \\
.0020\end{array}$ & $\begin{array}{l}0.25 \mathrm{amp} / \mathrm{dm}^{2} \text {. Ammoniacal ammonium sulfate-sulfite } \\
\text { electrolyte. }\end{array}$ \\
\hline $\begin{array}{r}0.2500 \\
.2500 \\
2.0000 \\
2.0000 \\
3.0000 \\
3.0000\end{array}$ & $\begin{array}{l}.0551 \\
.0551 \\
.4408 \\
.4408 \\
.6612 \\
.6612\end{array}$ & $\begin{array}{l}.0555 \\
.0562 \\
.4433 \\
.4438 \\
.6648 \\
.6646\end{array}$ & $\begin{array}{l}.0005 \\
.0006 \\
.0008 \\
.0067 \\
.0007 \\
.0006\end{array}$ & $\begin{array}{l}.0003 \\
.0003 \\
.0015 \\
.0017 \\
.0020 \\
.0020\end{array}$ & $\begin{array}{l}.0557 \\
.0565 \\
.4426 \\
.4428 \\
.6635 \\
.6632\end{array}$ & $\begin{array}{l}.0006 \\
.0014 \\
.0018 \\
.0020 \\
.0023 \\
.0020\end{array}$ & $\begin{array}{l}0.4 \mathrm{amp} / \mathrm{dm}^{2} \text {. Ammoniacal ammonium sulfate-sulfite } \\
\text { electrolyte. }\end{array}$ \\
\hline $\begin{array}{r}0.2500 \\
.2500 \\
1.0000 \\
2.0000 \\
2.0000 \\
3.0000 \\
3.6000\end{array}$ & $\begin{array}{l}.0551 \\
.0551 \\
.2204 \\
.4408 \\
.4408 \\
.6612 \\
.6612\end{array}$ & $\begin{array}{l}.0551 \\
.0556 \\
.2206 \\
.4415 \\
.4409 \\
.6613 \\
.6614\end{array}$ & $\begin{array}{l}.0006 \\
.0006 \\
.0004 \\
.0006 \\
.0007 \\
.0008 \\
.0008\end{array}$ & ' & $\begin{array}{l}.0557 \\
.0562 \\
.2210 \\
.4421 \\
.4416 \\
.6621 \\
.6622\end{array}$ & $\begin{array}{l}.0006 \\
.0011 \\
.0006 \\
.0013 \\
.0008 \\
.0009 \\
.0010\end{array}$ & $\left\{\begin{array}{l}0.25 \mathrm{amp} / \mathrm{dm}^{2} \text {. Ammoniacal ammonium chloride- } \\
\text { hydroxylamine hydrochloride electrolyte. }\end{array}\right.$ \\
\hline $\begin{array}{r}0.2500 \\
.2500 \\
1.0000 \\
2.0000 \\
2.0000 \\
3.0000 \\
3.0900\end{array}$ & $\begin{array}{l}.0551 \\
.0551 \\
.22 C 4 \\
.4408 \\
.4408 \\
.6612 \\
.6612\end{array}$ & $\begin{array}{l}.0554 \\
.0554 \\
.2206 \\
.4416 \\
.4412 \\
.6616 \\
.6612\end{array}$ & $\begin{array}{l}.0006 \\
.0004 \\
.0005 \\
.0007 \\
.0006 \\
.0006 \\
.0009\end{array}$ & ' & $\begin{array}{l}.0560 \\
.0558 \\
.2211 \\
.4423 \\
.4418 \\
.6622 \\
.6621\end{array}$ & $\begin{array}{l}.0009 \\
.0007 \\
.0007 \\
.0015 \\
.0010 \\
.0010 \\
.0009\end{array}$ & $\begin{array}{l}0.4 \mathrm{amp} / \mathrm{dm}^{2} \text { Ammoniacal ammonium chloride- } \\
\text { hydroxylamine hydrochloride electrolyte. }\end{array}$ \\
\hline $\begin{array}{r}0.2500 \\
.2500 \\
3.0000 \\
3.0000\end{array}$ & $\begin{array}{l}\text { 1. } 0551 \\
\text { 1. } 0551 \\
\text { 2. } 6612 \\
\text { 2. } 6612\end{array}$ & $\begin{array}{l}.0552 \\
.0556 \\
.6620 \\
.6616\end{array}$ & $\begin{array}{l}.0603 \\
.6005 \\
.0003 \\
.0006\end{array}$ & (n) & $\begin{array}{l}.0555 \\
.0561 \\
.6623 \\
.6622\end{array}$ & $\begin{array}{l}.0004 \\
.0010 \\
.0011 \\
.0010\end{array}$ & $\begin{array}{l}\text { Plated, with stirring, at } 1 \mathrm{amp} / \mathrm{dm}^{2} \text {. Ammoniacal } \\
\text { ammonium chloride-hydroxylamine hydrochloride } \\
\text { electrolyte. }\end{array}$ \\
\hline
\end{tabular}

13 -hr plating time. $\quad 27$-hr plating time.

TABLE 3. Results obtained for nickel, manganese, cobalt, and iron by the recommended procedure on a synthetic mixture approximating a high-temperature alloy and on a high-temperature alloy

\begin{tabular}{|c|c|c|c|c|c|c|c|c|c|c|c|c|}
\hline \multirow{2}{*}{ Sample number } & \multicolumn{3}{|c|}{ Nickel } & \multicolumn{3}{|c|}{ Manganese } & \multicolumn{3}{|c|}{ Cobalt } & \multicolumn{3}{|c|}{ Iron } \\
\hline & Taken & Found & $\begin{array}{c}\text { Differ- } \\
\text { ence }\end{array}$ & Taken & Found & $\begin{array}{c}\text { Differ- } \\
\text { ence }\end{array}$ & Taken & Found & $\begin{array}{c}\text { Differ- } \\
\text { ence }\end{array}$ & Taken & Found & $\begin{array}{l}\text { Differ- } \\
\text { ence }\end{array}$ \\
\hline High-temperature alloy .... & $\begin{array}{r}g \\
0.2071 \\
.2070 \\
.2072 \\
.2070 \\
\\
\end{array}$ & $\begin{array}{c}g \\
0.2071 \\
.2072 \\
.2073 \\
.2071 \\
.2071 \\
.2070 \\
.2071 \\
.2069 \\
.2066 \\
.2067\end{array}$ & $\begin{array}{c}g \\
0.0000 \\
.0002 \\
.0001 \\
.0001\end{array}$ & $\begin{array}{c}g \\
0.0165 \\
.0165 \\
.0165 \\
.0165\end{array}$ & $\begin{array}{c}g \\
0.0165 \\
.0165 \\
.0166 \\
.0165 \\
.0164 \\
.0164 \\
.0164 \\
.0164 \\
.0163 \\
.0164\end{array}$ & $\begin{array}{c}g \\
0.0000 \\
.0000 \\
.0001 \\
.0000\end{array}$ & $\begin{array}{c}g \\
0.3970 \\
.3970 \\
.3972 \\
.3972\end{array}$ & $\begin{array}{c}\varrho \\
0.3971 \\
.3970 \\
.3977 \\
.3980 \\
.4286 \\
.4296 \\
.4290 \\
.4292 \\
.4288 \\
.4291\end{array}$ & $\begin{array}{c}g \\
0.0001 \\
.0000 \\
.0005 \\
.0008\end{array}$ & $\begin{array}{c}g \\
0.0193 \\
.0193 \\
.0193 \\
.0193\end{array}$ & $\begin{array}{c}g \\
0.0193 \\
.0192 \\
.0194 \\
.0193 \\
.0214 \\
.0215 \\
.0213 \\
.0213 \\
.0214 \\
.0213\end{array}$ & $\begin{array}{r}g \\
0.0000 \\
-.0001 \\
.0001 \\
.0000\end{array}$ \\
\hline
\end{tabular}


cobalt fraction. This loss may possibly be due to a photoreduction [1] of the iron similar to that occurring in the ether-extraction of ferric chloride, because ferrous iron is eluted sufficiently rapidly in $4 N$ hydrochloric acid to be collected in the cobalt fraction. The remainder was retained by the resin and could be recovered by elution after allowing the resin to equilibrate a day with the $1 N$ hydrochloric acid.

This slightly low recovery of iron appears to be largely due to the unfavorable diffusion characteristics [14] in the resin column. Qualitative experiments, using commercially available resins of 1 - to 10-percent divinylbenzene cross-linkage, indicate the diffusion rates to be more rapid at the 2-percent divinylbenzene level. However, these resins expand and contract so much in going through the analysis cycle that the operation of this type of column is not attractive. Further, a longer column is required, as the bands move much faster under comparable conditions of acidity. The use of colloidal aggregates of the higher cross-linkage resins may be the best answer for quantitative work with this particular type of resin, if the resins can be commercially prepared to allow reasonably rapid flow rates $(25 \mathrm{ml}$ or more per hour per square centimeter of cross section).

The results obtained in the analysis of an S-816 type alloy are given in table 3 . The values for nickel, manganese, and iron on synthetic control solutions are satisfactory, and good replication of values on the sample is evident, the iron difficulties not being serious at the percentage level of iron in this sample. The cobalt values are subject to the errors of the electrolytic method and are probably 0.5 to $0.8 \mathrm{mg}$ too high as recorded.

It may be mentioned that the ferricyanide titration procedure $[2,13]$ may prove somewhat more attrac- tive for the rapid determination of cobalt, particularly if good cobalt standards become available. However, it should be kept in mind that manganese interferes quantitatively in this procedure, and that chromium is a disturbing element and must usually be removed if present in any appreciable percentage. Furthermore, the ferricyanide method is limited to approximately 100- to 125-mg quantities of cobalt if good end points are to be obtained.

\section{References}

[1] S. E. Q. Ashley and W. M. Murray, Jr., Ind. Eng. Chem., Anal. Ed. 10, 367 (1938).

[2] B. Bagshaw and J. D. Hobson, Analyst 73, 152 (1948).

[3] R. C. Chirnside, H. J. Cluley, and P. M. C. Proffitt, Analyst 72, 351 (1947).

[4] W. Conrad Fernelius, Editor, Inorganic syntheses, vol. II, p. 217 (McGraw-Hill Book Co., Inc., New York, N. Y., 1946).

[5] W. H. Hillebrand, G. E. F. Lundell, H. A. Bright, and J. I. Hoffman, Applied inorganic analysis, 2d ed., p. 413 (J. Wiley \& Sons, Inc., New York, N. Y., 1953).

[6] W. H. Hillebrand, G. E. F. Lundell, H. A. Bright, and J. I. Hoffman, Applied inorganic analysis, $2 \mathrm{~d}$ ed., p. 413, footnote 26 , (J. Wiley \& Sons, Inc., New York,
N. Y., 1953).

[7] H. Kirtchik, Anal. Chem. 19, 55 (1947).

[8] K. A. Kraus and G. E. Moore, J. Am. Chem. Soc. 75, $1460(1953)$.

[9] K. A. Kraus, F. Nelson, and J. F. Baxter, J. Am. Chem. Soc. 75, 2768 (1953).

[10] K. A. Kraus, F. Nelson, and G. W. Smith, J. Phys. Chem. 58, 11 (1954).

[11] E. E. Maczkowske and J. L. Hague (unpublished data).

[12] G. E. Moore and K. A. Kraus, J. Am. Chem. Soc. 74, 843 (1952)

[13] J. J. Phelan, Gen. Elec. Rev. 42, 218 (1939),

[14] B. A. Soldano and G. E. Boyd, J. Am. Chem. Soc. 75, 6101 (1953).

Washington, July 21, 1954. 